\title{
FACTORES QUE INCIDEN EN EL TRASVASE INTERLINGÜÍSTICO DE LA METÁFORA EN EL DISCURSO PUBLICITARIO ${ }^{1}$
}

\author{
María Soledad Velasco Sacristán ${ }^{2}$
}

\begin{abstract}
Resumen: Este artículo analiza la problemática que entraña el trasvase interlingüístico de la metáfora en el discurso publicitario. En primer lugar se pasa revista a este problema investigador. A continuación se presentan las investigaciones que se han realizado al respecto $y$, a continuación, se plantea una posible metodología de análisis de diferentes factores intratextuales e intertextuales que influyen en el trasvase interlingüístico de la metáfora en el discurso publicitario y que pueden permitir ofrecer una sistematización de las posibilidades traslativas de la figura en el discurso publicitario. Finalmente se extraen una serie de conclusiones.
\end{abstract}

Palabras clave: Metáfora, traducción, publicidad

\begin{abstract}
In this paper we have analysed the problem of the interlinguistic transfer of metaphor in the discourse of advertising. First, we have introduced this research problem. Next we have presented different research investigations related to it and, then, we have proposed a possible methodology for analysing different intratextual and intertextual factors that have an influence on the interlinguistic transfer of metaphor in the discourse of advertising. This analysis will make it possible to offer a typology of the different metaphor translating possibilities in the discourse of advertising. Finally, some conclusions have been drawn.
\end{abstract}

Keywords: Metaphor, translation, advertising

\section{INTRODUCCIÓN}

El estudio de la traducción publicitaria se potenció a partir de la Segunda Guerra Mundial (Bueno García 2000: 17), pero aún hoy existen en su tratamiento numerosas lagunas que es preciso llenar. Una de las áreas que hasta la fecha no ha recibido la atención que merece es la de la traducción de la metáfora publicitaria. Se abren así una serie de interrogantes importantes sobre la traducción o trasvase interlingüístico de la metáfora en el discurso publicitario, a saber, ¿es posible traducir la metáfora publicitaria?, ¿a qué se debe su difícil traducción? Si es posible traducirla: ¿cómo? o ¿qué procedimientos se pueden emplear?

Bien mirado, el debate sobre la traducibilidad o intraducibilidad de la metáfora publicitaria es tan estéril como el de la traducibilidad e intraducibilidad de la poesía, el de la

\footnotetext{
Fecha de recepción: abril 2008.

Fecha de aceptación y versión final: septiembre 2008.

2 Senior Lecturer, Departamento de Filología Inglesa, Universidad de Valladolid; $₫$ marisol@emp.uva.es.
} 
traducibilidad e intraducibilidad de la publicidad, o el de la traducibilidad o intraducibilidad a secas. Como bien señala Duro Moreno:

todo el mundo sabe que hay textos intraducibles que llevan siglos traduciéndose (por ejemplo, los poéticos o sagrados) y textos traducidos mal traducidos que han corrido el acaso de lexicalizarse en la comunidad lingüística y cultura de llegada hasta un grado tal que se comportan como si hubieran estado ahí desde siempre. (2001:150)

En realidad más que de traducibilidad o intraducibilidad estamos ante el viejo problema de la equivalencia. La equivalencia es, como defienden, Rabadán Álvarez (1991) y Reiss y Vermeer (1984, trad. de 1996), entre otros muchos, la relación que existe entre un texto (o elemento textual) origen y un texto (o elemento textual) meta; se trata por tanto de una noción que se redefine para cada proceso de traducción. Parece, pues, obvio que la discusión acerca de si las metáforas publicitarias se pueden o no traducir no sólo no lleva a ninguna parte, sino que está totalmente superada como muestra el hecho de que éstas se traducen -en su totalidad, en parte o nada-, pero se traducen. Se podría pensar entonces que las metáforas publicitarias son menos complicadas de lo que parece y que, puesto que se traducen, quizás no es tan grande la problemática de su traducción. Nada más erróneo. Ejemplos de los riesgos y fracasos que han acompañado a una traducción inadecuada de una metáfora publicitaria se cuentan por miles. Sirvan de ejemplo los siguientes errores de traducción:

- La traducción que se hizo al español del eslogan de las líneas aéreas Braniff del original "Travel on leather" como "Viaje en cueros". Esta traducción literal del inglés pasa a interpretarse inevitablemente de forma metafórica en español, causando cuando menos asombro que se recurriera al "viajar desnudo" como argumento de promoción, que dista del original que resalta la comodidad de viajar sentados en asientos de piel (Trainor 2002: 85).

- Otro ejemplo muy conocido fue la traducción del eslogan de Pepsi "Come alive with the Pepsi generation" que fue traducido a una variedad de chino con el significado de "Pepsi will bring your ancestors back from the dead". En este caso la traducción literal al chino no fue capaz de retener las connotaciones metafóricas positivas del original en inglés $\mathrm{y}$, además, dio pie a connotaciones negativas en la lengua meta (Goddard 1998: 83).

- Otro ejemplo es la traducción también a una variedad de chino del eslogan "Kentucky Fried Chicken's finger lickin' good" que se entendía como "eat your finger off' (Goddard 1998: 83).

Pero de la misma forma hay que señalar que también se dan aciertos cuando el conocimiento del mercado y la sensibilidad publicitaria guían la mano del traductor (Ocaña y Yanguas 2002: 7). Por ejemplo:

- la traducción del nombre de un champú estadounidense (Pert), que hace referencia a la blancura del producto y que se tradujo al francés para el target canadiense francófono como Prêt, que alude a la efectividad del champú en cuestión. El color 
con el que se comercializó el producto en Canadá era de color verde y con un fresco aroma a hierba cortada (Tatilon 1990, citado por Valdés Rodríguez 2002b: 89).

Con todo, a algunos estudiosos, sobre todo de la traducción en general y en menor medida de la traducción publicitaria, les sigue inquietando la traducción de la metáfora, por constituir un foco de controversia que plantea grandes retos al investigador. Desde esta perspectiva, creemos que todavía sigue teniendo plena validez la cita que escribiera Newmark (1988: 113) sobre la traducción de la metáfora:

(...) the translation of any metaphor is the epitome of all translation, in that it always offers choices in the direction either of sense or of an image, or a modification of one, or a combination of both and depending, as always, on the contextual factors, not least on the importance of the metaphor within the text.

Así las cosas, cabe preguntarse ¿a qué se debe su dificultad de traducción? Probablemente a que se trata de un fenómeno de creación único e intransferible que presenta una dificultad añadida de decodificación en su propia lengua, y que, además, no nos ofrece ningún punto de referencia o consulta (los diccionarios no pueden reproducir algo que se encuentra en un continuo proceso de creación y fosilización), aparte del hecho de que la mayoría de las metáforas se hallan inmersas en una progresiva y vertiginosa lexicalización que desdibuja unas fronteras ya borrosas per se. A todo ello se suma un factor tan complejo como su estrecha relación con el sistema cultural e idiosincrásico de la civilización en que ha surgido. Además cada metáfora lleva tras de sí toda una serie de asociaciones implícitas que hay que reproducir de algún modo en la lengua meta (Samaniego Fernández 1996: 83). Junto a estas dificultades, y para agravar aún más la problemática que entraña la traducción de la metáfora en sí misma, en el caso de la figura en el discurso publicitario no solamente es versátil hasta el punto de aparecer bajo cualquier forma semiótica posible (monomodal o multimodal), dando lugar a realizaciones metafóricas verbales, pictóricas, verbopictóricas, pictóricoverbales, etc. (Forceville 1996, 2002, 2004, 2006), sino que además, como fenómeno cognitivo, se emplea para caracterizar principalmente el producto o servicio anunciado que es, por lo general, el primer término (literal o tenor ${ }^{3}$ ) de la metáfora con una serie de rasgos, más o menos relacionados con el mismo, que pueden variar culturalmente para cada producto o servicio (Cook 2001; Ungerer 2000), y que constituyen el segundo elemento (figurado o vehículo) de la metáfora; ambos elementos pueden aparecer explícitos o implícitos, siendo el cotexto y contexto cruciales para su interpretación; y como fenómeno pragmático, suele ser un elemento imprescindible para influir las opiniones y juicios de los receptores mediante la persuasión, con lo que se convierte en un importante recurso ideológico (cf. Fairclough 1989, 1995). Veamos dos ejemplos, extraídos de la base de datos "Anuncios 2002"4 que ilustran estas dificultades de traducción:

\footnotetext{
Esta terminología corresponde a Richards (1936): tenor y vehículo. Forceville (1996) usa primer elemento y segundo elemento.

4 Esta muestra fue empleada en el estudio empírico de mi tesis doctoral: "Publicidad y Género: Propuesta, diseño y aplicación de un modelo de análisis de las metáforas de género en la publicidad impresa en lengua inglesa", defendida en noviembre de 2002.
} 


\section{EJEMPLOS:}

\section{[1] LA FRAGANCIA DE VERANO ANUNCIADA ES AGUA DEL MAR}

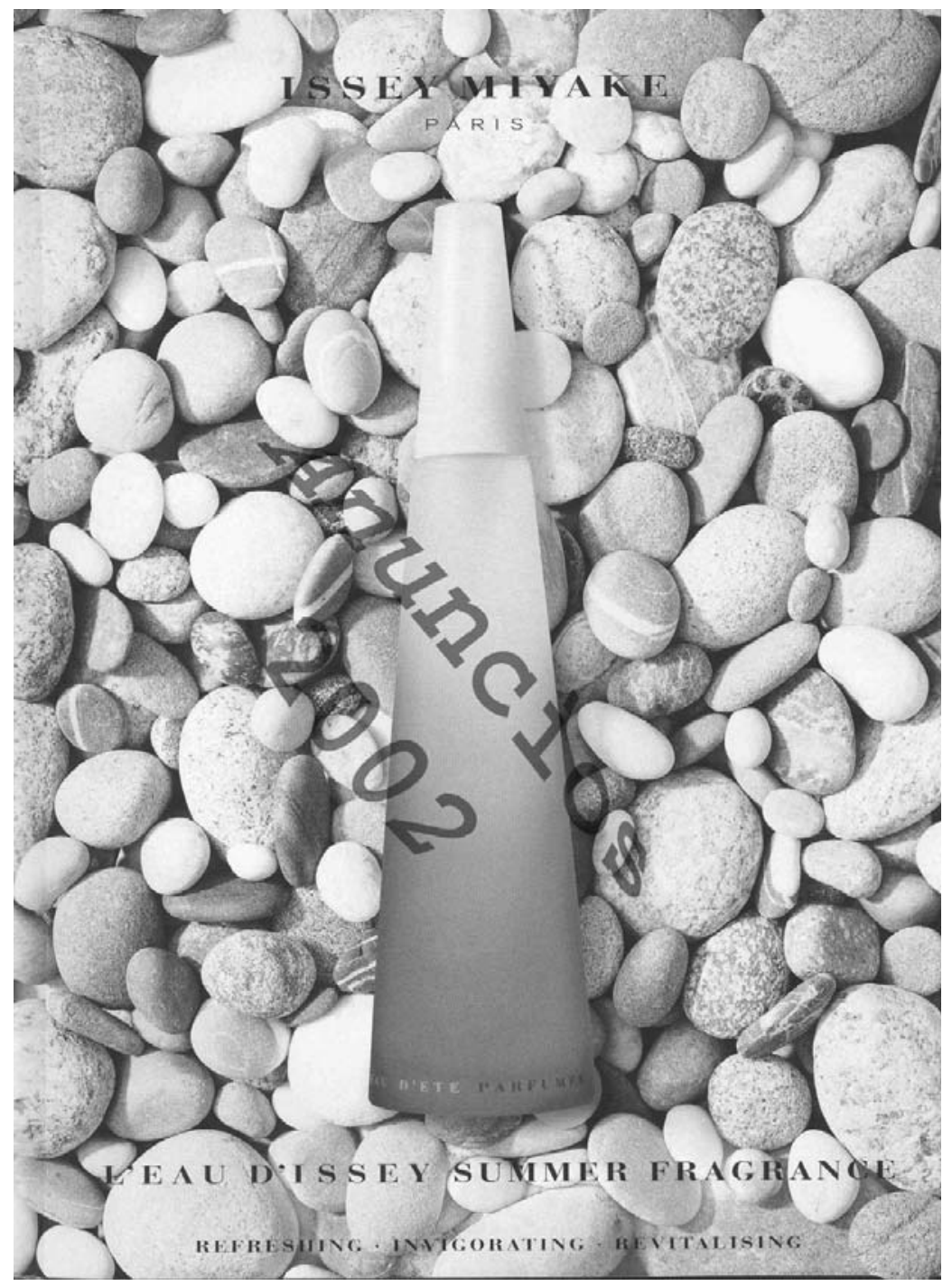

En esta metáfora queda clara la identificación de "la fragancia de verano" y "el agua del mar" que se realiza a nivel pictórico-verbal, gracias a la fotografía del anuncio y los elementos de cierre (nombre de la marca y eslogan). Las propiedades que se transfieren del "agua del mar" (vehículo) a la "fragancia de verano" (tenor) quedan explicitados a nivel verbal en el eslogan: "refreshing, invigorating, revitalising". No obstante, esta asociación resulta clara en países con diferencias claras de temperaturas en el verano y el invierno, algo que, por ejemplo, perdería parte de la asociación en países en los que hay continuamente temperaturas frías como en el clima polar (por ejemplo, Groenlandia), o aquellos en los que hay temperaturas muy calientes durante todo el año como en el clima tropical (por ejemplo,

\footnotetext{
5 Los ejemplos muestran la imagen escaneada de los anuncios en que se encuentran las metáforas. Cada uno de estos anuncios lleva una marca de agua con el nombre de la base de datos, Anuncios 2002, en la que se almacenaron para su empleo en mi tesis doctoral.
} 
Brasil), etc. En esos casos habría que cambiar la imagen, o quizá el contenido del eslogan (i.e. adaptación), o por qué no, crear un nuevo anuncio (i.e. creación).

\section{[3] EL HELADO DE FRESA ANUNCIADO ES UN MATRIMONIO DE FRUTA E HIELO}

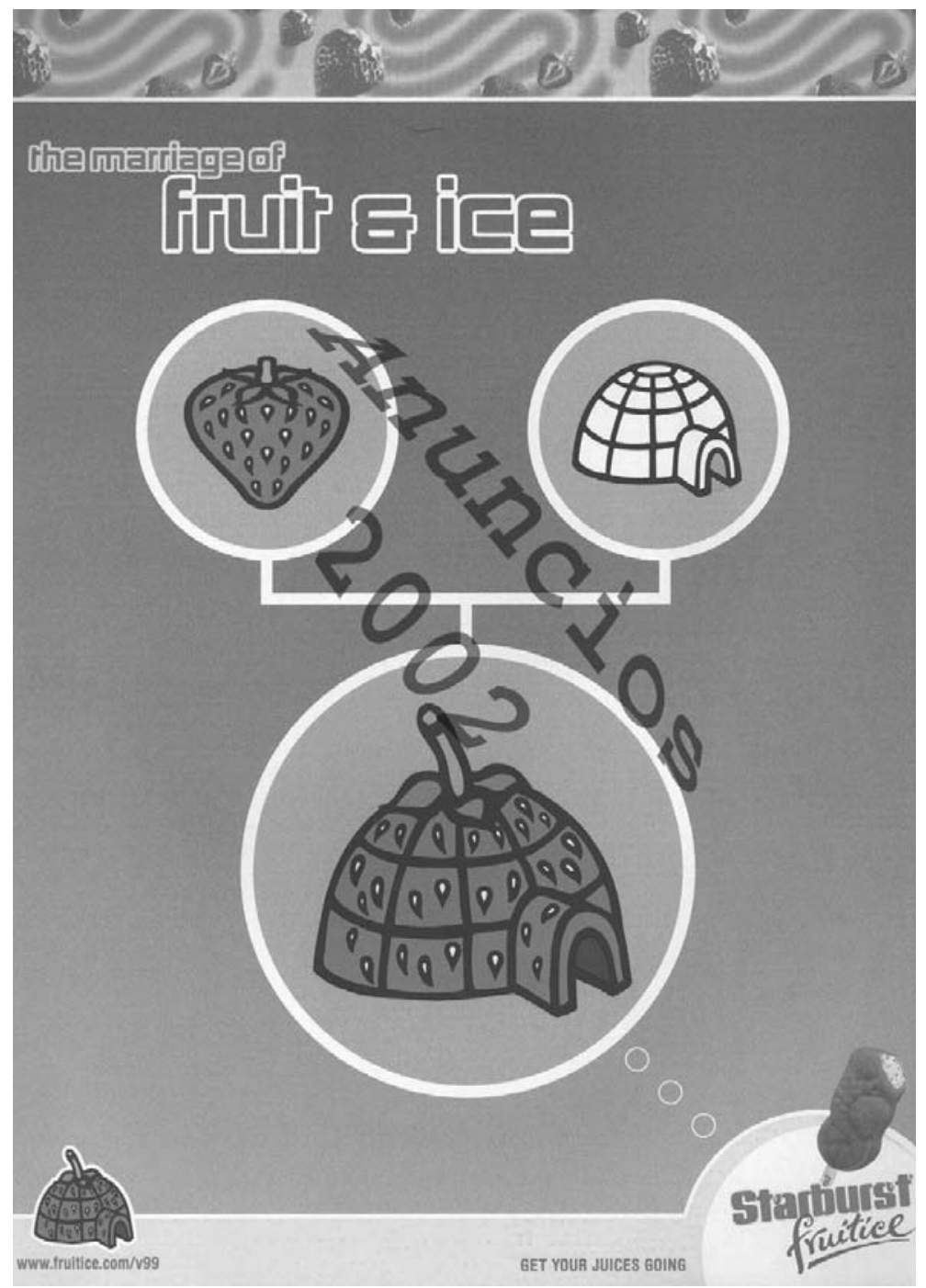

En esta metáfora se produce la identificación del "helado anunciado" y "el matrimonio de una fresa y un iglú" que se realiza a nivel verbo-pictórico gracias al titular (e.g. the marriage of fruit and ice) y marca del producto (i.e. Fruitice) del anuncio y su ilustración (organigrama que es una especie de árbol genealógico que presenta un dibujo de una fresa y un iglú en el nivel superior y una especie de iglú de fresa que resulta del "matrimonio de la fresa y el iglú", como si fuera un hijo, en el nivel inferior). Las propiedades que se transfieren del "la fresa y el iglú" (tenor) al helado de fresa (vehículo) son probablemente "el sabor de la fruta y la frescura" y la "vitalidad" como podemos deducir del eslogan ("Get your juices going”). En esta metáfora vemos claras implicaciones ideológicas como, por 
ejemplo, la idea tradicional del matrimonio y los hijos como podemos deducir del titular y el árbol genealógico, pero esta implicación pierde fuerza en aquellas sociedades en las que el matrimonio no se considera excesivamente importante para tener hijos por lo que en su traducción se podría optar por cambiar el término "matrimonio" u otra posibilidad traslativa, y quizá haya que modificar también la ilustración, con lo que se puede tratar simplemente de adaptar o de crear un nuevo anuncio.

Finalmente, queda exponer la problemática del trasvase traslativo de esta figura, o más concretamente, ¿cómo se traduce la metáfora? o ¿qué estrategias se pueden emplear para traducir la metáfora en general y la metáfora publicitaria en particular? Como respuesta a estos interrogantes se puede decir que la mayoría de autores que han abordado el estudio de la metáfora coinciden en señalar tres opciones generales en la traducción de la metáfora: reproducir la misma metáfora en la lengua meta, sustituirla por otra metáfora en la lengua meta; o recurrir a la paráfrasis (significado) (Van den Broeck 1981; Newmark 1988, 1991; Toury 1985, 1995; Dobrzynska 1995), a las que se han añadido otras opciones como, por ejemplo, traducirla por un símil, un símil más paráfrasis, omitirla o reproducir la misma metáfora más paráfrasis (sólo en la lengua meta) (Newmark 1988, 1991) o, por ejemplo, pasar a traducir como una metáfora lo que no era una metáfora en la lengua origen o la omisión en la lengua origen de una metáfora en la lengua meta (Toury 1985, 1995).

Como vemos, estas opciones planteadas para llevar a cabo el trasvase de la metáfora de una lengua y cultura origen a una lengua y cultura meta parecen tener en mente sólo la metáfora verbal por lo que no parecen ser operativas para hacer frente a la diversidad de códigos y medios de los que se sirve la metáfora con realización monomodal y multimodal en el caso concreto del discurso publicitario en el que se precisan estrategias traslativas más acordes con el tipo de traducción publicitaria, que se considera un caso particular de traducción subordinada (Mayoral Asensio, Kelly y Gallardo San Salvador 1986, 1998, 1999), que es el tipo de traducción en la que intervienen varios códigos y/o medios. Por ello habrá que considerar estrategias que combinen la atención al componente verbal y no verbal, así como la conjunción de ambos.

De esta última problemática, relativa a las estrategias traslativas de la metáfora publicitaria, se desprende la necesidad apremiante de una sistematización de las posibilidades traductivas que presenta la figura en el discurso publicitario atendiendo a las peculiaridades de cada canal y soporte en el que se imbrica el mismo. Esta sistematización ha de ser flexible para adaptarse a la versatilidad de la figura en el discurso publicitario. Es esta necesidad la que nos inspiró la idea germen del presente artículo y el área problemática de estudio que aborda.

\section{ESTADO DE LA CUESTIÓN}

El gran inconveniente de los estudios publicados sobre la traducción de la metáfora ha sido la escasez que hay de dichas publicaciones. Apenas si contamos con investigaciones monográficas, las contribuciones existentes son pequeños capítulos incluidos en obras sobre la traducción en general o sobre semántica (Samaniego Fernández 1996: 19). Esta escasez se torna prácticamente en ausencia al referirnos a estudios concretos sobre la traducción de la metáfora en el discurso publicitario. Salvo menciones puntuales al tema en estudios sobre 
el discurso publicitario y sobre la traducción del mismo apenas hay artículos concretos y específicos sobre el tema.

Así las cosas, la mayoría de los autores dentro de los estudios de traducción de la metáfora adoptan las investigaciones sobre la metáfora que se han hecho desde la lingüística o la filosofía. Coexisten de este modo aproximaciones tradicionalistas (literalismo) y cognitivas (figuralismo). El literalismo estudia la metáfora como un fenómeno retórico léxico, propio de la semántica que es artificial, anómalo, periférico y fácilmente sustituible por una paráfrasis literal (Aarts y Calbert 1979; Ortony 1979; Searle 1979; MacCormac 1985). El figuralismo estudia la metáfora como fenómeno conceptual de naturaleza cognitiva, central, sistemática y necesaria (Lakoff y Johnson 1980; Lakoff y Turner 1989; Sweetser 1990; Indurkhya 1992). Antes del siglo XX los estudios sobre la metáfora adoptaban casi exclusivamente el primer enfoque, pero a partir del siglo XX con Richards (1936) y después con Lakoff y Johnson (1980) se afianzan los principios defendidos por el figuralismo.

En lo que respecta a los estudios de traducción se puede hablar también de dos tendencias, que asimismo han influido en los estudios sobre la traducción de la metáfora; por un lado, los modelos prescriptivistas, que hablaban de modelos de traducción a seguir (House 1977, 1981; Newmark 1988, 1991) y los modelos más actuales, descriptivistas, que antes de hacer afirmaciones gratuitas tratan de analizar los hechos reales de traducción (Toury 1980, 1985, 1995; Rabadán Álvarez 1991).

De la conjunción de estas posturas, sobre la metáfora y la traducción, surgen dos tipos de aproximaciones al trasvase interlingüístico de la metáfora: los estudios prescriptivoliteralistas, que hablan de modelos a seguir en la traducción de la metáfora (cf. Newmark 1988); y los estudios descriptivo-figuralistas, que de forma gradual han ido adaptándose a los cambios que introdujeran Lakoff y Johnson (1980) sobre la metáfora en línea también con las aportaciones de los estudios más descriptivos de traducción, derivando hacia una aproximación descriptiva de traducción de la metáfora (cf. Toury 1995), que analiza casos reales, en este caso concreto, las dificultades específicas de la metáfora y las soluciones que los traductores dan a éstas (Samaniego Fernández 2002, 2007; Schäffner 2004). Junto a esas dos posturas convive una tercera postura, una aproximación ecléctica o de transición (Samaniego Fernández 2002, 2005). Se pueden dividir, por tanto, en tres las aproximaciones hechas a la metáfora desde los estudios de traducción: aproximación tradicionalistaprescriptiva, aproximación ecléctica y aproximación funcionalista-descriptiva.

La aproximación tradicionalista-prescriptiva se caracteriza por considerar a la metáfora una figura decorativa y por distinguir entre lenguaje literal y metafórico, siendo este último considerado como desvío. Podemos citar dentro de esta corriente a Nida y Taber (1969), Vázquez Ayora (1977), Newmark (1988), Azar (1989), Larson (1989), Pliego Sánchez (1993), Álvarez Calleja (1993) y Torre (1994).

La aproximación ecléctica tiende hacia el figuralismo y descriptivismo, pero sigue presentando rasgos tradicionalistas, por lo que se trata de un enfoque de transición. Podemos mencionar aquí a autores como Dagut (1976), Van den Broeck (1981), Mason (1982), Fung y Kiu (1987) y Menacere (1992).

En la aproximación figuralista-descriptiva, que muestra una postura inclinada hacia el figuralismo y hacia un punto de vista descriptivo-funcional respecto a la traducción, entraría un buen número de contribuciones, entre las que se cuentan Snell-Hornby (1988), 
Van Besien y Pelsmaeckers (1988), Pisarska (1989), Rabadán Álvarez (1991), Stienstra (1993), Kurth (1995), Schäffner (1997, 1998), Cristofoli, Dyrberg y Stage (1998), Fuertes Olivera y Samaniego Fernández (1998), Al Harrasi (2000), Boquera Matarredona (2000), Samaniego Fernández (2000), Fuertes Olivera y Velasco Sacristán (2001), Fuertes-Olivera y Pizarro-Sánchez (2002) y Schäffner (2004).

Por lo que se refiere al estado de la cuestión de estudios sobre la traducción de la metáfora en el discurso publicitario hay que señalar que las contribuciones existentes son bastante escasas. Provienen de estudios generales de introducción a la metáfora (Knowles y Moon 2006), de estudios generales sobre el discurso publicitario (Cook 2001; Campos Pardillos 1998; Goddard 1998), de estudios sobre la traducción del discurso publicitario (Bueno García 2000; Edwards 2002) o de estudios sobre figuras retóricas, especialmente la metáfora, en el discurso publicitario (Velasco Sacristán 1999; Vandaele 2002; Martínez Belchí y Rocamora 2005).

Como podemos deducir de la exposición de estos antecedentes, ni desde los Estudios de Traducción, ni desde los estudios del discurso publicitario, ni desde el estudio de la traducción publicitaria, ni desde los estudios de figuras retóricas en el discurso publicitario se alcanza a llenar todas las lagunas que es preciso llenar a la hora de abordar el estudio de la traducción de la metáfora en el discurso publicitario que se ha de abordar, en nuestra opinión, desde una perspectiva figuralista y descriptiva. Se echa en falta una visión integrada de la metáfora que alcance a explicar la metáfora en sus múltiples facetas en el discurso publicitario a nivel discursivo (más concretamente semiótico), cognitivo y pragmático y su trasvase interlingüístico a otras lenguas y culturas.

\section{METODOLOGÍA DE ANÁLISIS PARA LOGRAR UNA SISTEMATIZACIÓN DE LAS POSIBILIDADES TRASLATIVAS DE LA METÁFORAEN EL DISCURSO PUBLICITARIO}

La hipótesis de la que partimos en este artículo se apoya en los estudios figuralistas de la metáfora, que entienden la figura como un fenómeno discursivo, de carácter cognitivopragmático que es central, sistemático y necesario (Lakoff y Johnson 1980; Lakoff y Turner 1989; Sweetser 1990) y los estudios descriptivos de traducción, que plantean una orientación hacia el texto meta y el análisis de un corpus coherente de textos traducidos y de fuentes extratextuales, o paratextos, que contengan afirmaciones críticas y teóricas sobre la traducción. Nos servimos muy especialmente de las aproximaciones polisistémicas [especialmente Even-Zohar $(1979,1981)$ y Toury $(1978,1980,1985,1995)]$, la Escuela de la Manipulación [Rabadán Álvarez (1991)], así como el enfoque funcionalista [Reiss y Vermeer (1984, trad. de 1996)]. La corriente comunicativa e intercultural [Hatim y Mason (1990, 1997) y Valdés Rodríguez (1997, 1998a, 1998b, 2000, 2002a, 2002b)] y la aproximación de la traducción subordinada [Mayoral Asensio, Kelly y Gallardo San Salvador (1986, 1998, 1999)]. Partimos de la hipótesis de que la metáfora publicitaria es traducible en tanto en cuanto se le puede dar respuesta discursiva, cognitiva y pragmática a nivel interlingüístico. Lo realmente importante es evaluar las consecuencias comunicativas que tiene cada tipo de trasvase, así como ver la validez relativa del modelo de traducción que se ha elegido respecto de las normas vigentes del sistema meta. 
Como se puede observar en esta hipótesis, creemos que la metáfora publicitaria es traducible, aunque presenta un grado alto de inequivalencia interlingüística (Newmark 1988, 1991; Van den Broeck 1981; Toury 1985, 1995; Rabadán Álvarez 1991; Samaniego Fernández 1996, 1998a, 1998b, 2000, 2002, 2007). La metáfora constituye un aspecto necesario del trasvase intercultural de la publicidad, que pone en relación las circunstancias de producción de la metáfora en el texto origen como acto comunicativo, con las circunstancias de la traducción y los fines que ésta persigue (Hatim y Mason 1990, 1997). Asimismo es necesario preservar la función pragmática de la metáfora origen (Reiss y Vermeer 1986, trad. de 1996) y atenerse a las normas del polisistema meta que modela el proceso de traducción en el caso del discurso publicitario (Toury 1980, Rabadán Álvarez 1991). En este sentido, tradicionalmente se ha considerado la traducción publicitaria como ejemplo típico de aceptabilidad (Toury 1985, 1995) o traducción comunicativa (Newmark 1988) en el que la traducción se inclina hacia el polo de la lengua y la cultura meta, convirtiéndose en muchos casos en pura creación que no guarda relación alguna con el texto origen, pero que preserva la función del texto origen. Por consiguiente, tanto la noción del escopo (finalidad) del enfoque funcional como la prioridad al TM del descriptivo serán operativas en nuestra investigación. También será necesario considerar la superposición de códigos semióticos, que es un caso particular y concreto de la traducción subordinada (Mayoral Asensio, Kelly y Gallardo San Salvador 1986, 1998, 1999).

Esta hipótesis general de trabajo sobre la posible traducibilidad de la metáfora es muy genérica y para tratar de demostrarla se ha de estudiar la metáfora y su trasvase interlingüístico en pares concretos de lenguas y después hacer avanzar esta hipótesis, que en cualquier caso habrá de ser contrastada en el futuro con muestras más amplias (por ejemplo de textos publicitarios en diversos canales y/o lenguas diferentes).

Para el análisis de los textos publicitarios paralelos de la muestra a estudiar, se ha de seguir una metodología descriptiva, que muestre las normas traductoras (regularidades de comportamiento) que se han seguido al traducir esos anuncios. Asimismo se han de combinar modelos de análisis textual orientados a la traducción, los postulados de la lingüística del texto y el análisis del discurso, la textología y la retórica contrastivas, desde una perspectiva traductológica eminentemente funcional. Para ello se puede seguir un modelo de análisis descendente (top-down) del estilo empleado por Cook (2001) para analizar el discurso publicitario, tal y como lo adoptó Corpas Pastor (2002) en su metodología de análisis y documentación para la traducción de textos publicitarios, en que la autora empleó también tres niveles, pero una configuración interna diferente de Cook y donde el texto meta ocupa un lugar primordial.

Las variables de ese modelo son las siguientes: primero las coordenadas espaciotemporales del anuncio y los agentes implicados, esto es, el contexto de situación tanto del texto origen (TO) como del texto meta (TM), atendiendo ahí a factores como los participantes, el medio, el canal, el modo, las coordenadas espacio-temporales de la comunicacion y el motivo de la comunicación. Dado que se trata de un análisis orientado a la traducción tendremos en cuenta también el escopo, esto es, los condicionantes extratextuales que influyen en la estrategia global de traducción, con especial referencia a las restricciones (textuales, socioculturales, traslativas y legales) que afectan a la traducción publicitaria y que determinan las normas sincrónicas del polisistema meta. A partir de ahí procederemos 
a estudiar variables como la unidad textual origen (TO) desde los niveles superiores del análisis (tema, macroestructura, función textual, acto textual, tipo textual, superestructura, recursos retóricos y elementos no verbales) con vistas también a la producción del texto meta. Aquí al identificar una metáfora, según los criterios de identificación discursiva de las metáforas conceptuales que propone Steen (1999), y que presentamos después, estudiaremos los parámetros de variación que presenta para el trasvase interlingüístico de la metáfora Samaniego Fernández (1996: 133-135), que también presentamos posteriormente. Finalmente, descenderemos a los niveles inferiores o internos del TO (variables de la pragmática, sintaxis y gramática, léxico y semántica, y elementos suprasegmentales), con objeto de prever problemas puntuales y específicos de traducción (problemas como, por ejemplo, en relación con las especificaciones o restricciones). En este punto seguiremos las teorías funcionalistas de Reiss y Vermeer (1984, trad. de 1996), Vermeer (1989) y Nord (1994) para atender a los efectos comunicativos del trasvase.Por lo que respecta a la identificación de las metáforas en la muestra se puede seguir a Steen (1999), quien propone cinco pasos para la identificación discursiva de metáforas conceptuales, a saber, identificación del vehículo de la metáfora (implícito o explícito), identificación del tenor de la metáfora (también implícito o explícito), identificación de la comparación no literal, identificación de la analogía no literal, e identificación del mapping no literal. En esta etapa de identificación discursiva se tiene que tener además en cuenta que tanto el vehículo como el tenor de la metáfora pueden aparecer en el discurso publicitario en variedad de modos (medios y/o códigos) dando lugar a realizaciones metafóricas monomodales (verbales o no verbales) y multimodales (verbopictóricas, pictóricoverbales, etc.) (Forceville 1996, 2002, 2004, 2006). Veamos cómo se puede proceder a esta identificación con el ejemplo 1 que mostrábamos anteriormente: LA FRAGANCIA DE VERANO ANUNCIADA ES AGUA DEL MAR

- Identificación del vehículo de la metáfora: El agua del mar (implícita en el anuncio); en el anuncio la fotografía muestra claramente que el agua del mar no está siendo usada en sentido literal ya que aparece sustituida por la fotografía del frasco de la fragancia anunciada.

- Identificación del tenor de la metáfora: La fragancia de verano anunciada (explícita en la fotografía del anuncio). Su superposición en el lugar del agua del mar muestra claramente la identificación con la misma. Además habitualmente se habla de "agua" para referirse a fragancias o perfumes en expresiones lexicalizadas como "agua de perfume" (eau de parfum) o "agua de colonia" (eau de toilette), aquí encontramos una elaboración de esa metáfora conceptual base ya que se trata de una fragrancia en una variedad más fresca para el verano y el agua es "agua del mar" que es una metonimia ("ir a la playa en verano"), una especie de "causa por el efecto" ("el verano por el ir a la playa").

- Identificación de la comparación no literal: "La fragancia de verano anunciada es como agua del mar". Como vimos anteriormente, el agua del mar puede entenderse como una metonimia del verano $\mathrm{y}$, por tanto, considerarse adecuada para una fragancia con una variedad fresca que se lleva en verano, se trata de una elaboración específica de la metáfora genérica lexicalizada "EL PERFUME ES AGUA". 
- Identificación de la analogía no literal: la principal propiedad que se pueden atribuir en la identificación anterior sería "frescor".

- Identificación del mapping no literal: aquí se completan las propiedades que se pueden transferir del vehículo al tenor de la metáfora, y que en nuestro caso quedan concretadas por el eslogan ("refreshing, invigorating, revitalising"): frescor, tonificación, revitalización.

Una vez identificadas las metáforas de la muestra se pueden proceder a analizar los siguientes factores de variación (variables adaptadas de Samaniego Fernández 1996: 133-135):

- Las asociaciones semánticas que tenga la figura en sus dos variantes: LO y LM, analizando las connotaciones que despierta la metáfora en cada lengua, y su posible equivalencia. En el ejemplo analizado anteriormente, las connotaciones que despierta la metáfora en lenguas como, por ejemplo, el español y el inglés es, como señalábamos antes principalmente el frescor, seguido por la tonificación y la revitalización.

- La carga informativa de la metáfora, es decir, si ésta se complica con otros elementos (verbales o no verbales) que pueden llegar a poner serios obstáculos a su trasvase, como pueden ser una amalgama de referencias culturales, juegos de palabras, imágenes, etc. Y de ser así, en qué medida éstas son compartidas por la LO y la LM, así como la relación entre el sistema etnolingüístico -origen y meta- y la traducción de la figura. También incluiremos en este apartado un estudio del grado en el que el compartimiento de campos culturales entre ambas civilizaciones facilita $-\mathrm{O}$ dificulta- la traducción. Aquí se podría hablar de la metáfora que presentábamos en el ejemplo número 2, en el que, como mencionábamos entonces hay referencias culturales al matrimonio y al tener hijos dentro del mismo, esa idea es en similar medida compartida en inglés y en español.

- El propósito comunicativo en sus distintas variables: propósito o intención del autor original (anunciante), de la agencia publicitaria, de la empresa o particular que emprende la traducción, del traductor de la traducción en sí e incluso el propósito que tiene en mente el destinatario ${ }^{6}$ de la traducción a la hora de emprender la lectura del TM. En este caso, en relación al ejemplo 2, suponemos que el propósito o intención del autor original (anunciante), de la agencia publicitaria, de la empresa o particular que emprende la traducción, del traductor de la traducción en sí e incluso el propósito que tiene mente el destinatario pueden variar ya que la metáfora del anuncio original está claramente relacionada con la marca del producto y, como debido al copyright, no se suele traducir a ninguna lengua, salvo que el receptor de la lengua meta sepa la lengua origen, inglés en este caso, se perderá esa asociación.

- La relevancia funcional de la metáfora en el anuncio en que se encuentra inserta, analizando si ésta es prescindible, si es esencial para el anuncio, etc. Como veíamos antes, en relación a la metáfora del ejemplo 2, la idea del matrimonio para la realización de la fusión de "la fruta" y "el hielo" (marca: Fruitice) se podría haber omitido aunque se podría mantener, por ejemplo, el árbol genealógico.

\footnotetext{
6 En este caso se han de realizar entrevistas a una muestra de receptores de la metáfora, compuesta por un grupo representativo de receptores potenciales del medio en el que aparece la metáfora (original y su traducción).
} 
- La "distancia" cognitiva que intuitivamente existe entre el objeto o ente real al que hace referencia y las metáforas que se utilizan para designarlo. En este caso, en la metáfora del primer ejemplo la distancia cognitiva entre "el agua del mar" y "la fragrancia de verano" es muy pequeña, comparada, por ejemplo, con la metáfora del segundo ejemplo en que la distancia cognitiva entre "el helado de fresa" y "el matrimonio de fruta e hielo" es mayor.

- La existencia de asociaciones previas ya establecidas entre el objeto o ente real y la metáfora. En este caso, en el primer ejemplo, como comentábamos antes, existen unas asociaciones previas entre "el agua del mar" y "el perfume" (e.g. "estado líquido", "frescor", etc.) que dan lugar a una metáfora que se observa en expresiones lexicalizadas, como por ejemplo, "agua de perfume" o "agua de colonia".

- El lector meta potencial que el traductor tenga en mente y el conocimiento que el traductor dé por sentado que va a tener su lector sobre la cultura origen. Esta característica puede ser interesante, sobre todo, en la metáfora del ejemplo 2, en todo lo relativo al concepto cultural del "matrimonio" que el traductor dé por sentado que va a tener su lector sobre la cultura origen.

- El grado de explotación de los recursos verbales (rasgos formales o peculiaridades estructurales de la LO), no verbales (imágenes, olores ${ }^{7}$, etc.) o híbridos (rasgos formales más imagen, olor más imagen, etc.), junto con el análisis de la medida en que el compartimiento de esos recursos permite -o no- el trasvase. En este caso, el uso del texto y de la imagen, tanto en el ejemplo 1 como en el ejemplo 2 puede permitir el trasvase sin problema en cada uno de los dos casos.

- El grado de interpretabilidad de la figura en la LO, así como un estudio de casos en que la figura sea interpretable pero las estructuras -discursivas, bien verbales, no verbales o híbridas, o conceptuales- de la LM no permitan el trasvase. Aquí habría que tener en cuenta, de nuevo, si el término "matrimonio" de la metáfora del segundo ejemplo ha de mantenerse, omitirse o cambiarse.

- Las restricciones contextuales que dificulten la traducción de la figura, así como un estudio de la cantidad de contexto necesario para la comprensión de ésta. En las dos metáforas aquí analizadas se precisa más o menos del mismo contexto para lograr la comprensión de la figura. Aunque en el caso de la metáfora del ejemplo 2 habría que salvar el escollo del nombre de la marca en inglés, quizá con una traducción literal de la misma junto al original para que se comprenda mejor la figura.

- La tipología de la metáfora según su forma externa y si dicha clasificación influye de modo relevante en su "traducibilidad". En la metáfora del ejemplo 1 tenemos una recreación de una metáfora muy lexicalizada ("EL PERFUME ES AGUA”) y en su trasvase se puede optar sin problemas por mantener la recreación de esa metáfora lexicalizada. En el segundo ejemplo, sin embargo, tenemos una metáfora creativa y en su trasvase podemos optar por mantenerla o cambiarla por otra metáfora creativa, por ejemplo.

Por ejemplo en aquellos anuncios impresos de perfume con prueba de olor desplegable. 
- Las restricciones que impone el sistema etnológico sincrónico, es decir, la influencia de factores como el canon estético, las convenciones, la censura, las normas éticas o religiosas, la educación, etc. Aquí habría que tener en cuenta lo que podría suponer si se opta, por ejemplo, por omitir la idea del "matrimonio" en la metáfora del segundo ejemplo en su trasvase a determinadas culturas.

- La influencia de la tipología textual respecto de la traducción de la figura, y dentro de cada tipo, los distintos grados de traducibilidad según los estilos que se empleen en el anuncio (narración, diálogo, descripción). En los dos ejemplos analizados la influencia de la tipología textual utilizada (narración) se puede mantener en el trasvase con un alto grado de traducibilidad.

- El peso del "registro" en la traducción, con un análisis del grado de equiparación alcanzado entre la LO y LM. De nuevo el análisis del "registro" para la traducción de las dos metáforas de los ejemplos considerados aquí no parece que vaya a dar problemas en el trasvase.

- El grado de lexicalización de la metáfora en ambas lenguas, teniendo en cuenta el uso lingüístico y las diferencias estructurales y de conceptualización entre los dos idiomas. Aquí ya hemos mencionado que en el caso de la metáfora lexicalizada el trasvase es bastante fácil (ejemplo 1), pero en el caso de la metáfora creativa (ejemplo 2) se puede optar por mantener la metáfora del original o crear una nueva, ya que la identificación entre el tenor y el vehículo es nueva en ambas culturas.

- La influencia inconsciente que puedan tener las estructuras de la LO (verbales o no verbales) en la LM a través del traductor. Por ejemplo, si se produce una omisión o cambio de algún elemento verbal (e.g. término "matrimonio") o pictórico ("árbol genealógico") en el trasvase de la metáfora del ejemplo 2.

- Otros factores ${ }^{8}$ : el plazo de que dispone el traductor para el trasvase interlingüístico, el material de referencia de que dispone el traductor, los cambios estilísticos de post-edición realizados por personas ajenas a éste, el factor idiolectal, el factor denominado de "humor", la competencia del traductor tanto en la lengua y cultura origen como en la meta, las condiciones implícitas por la entidad que encarga la traducción; la valoración que hace el traductor del lector medio potencial que va a ser destinado de su trabajo; el inevitable factor pecuniario, etc. Todos estos aspectos habría que investigarlos en relación a las dos metáforas aquí consideradas.

A continuación, se han de recapitular las estrategias traslativas seguidas y a evaluar las consecuencias de las mismas en cada trasvase. Finalmente se podrá llevar a cabo una sistematización de posibilidades traslativas de la metáfora publicitaria que sean aplicables a los diferentes soportes publicitarios en los diferentes canales publicitarios.

\footnotetext{
8 Estos datos no son, desafortunadamente, accesibles directamente para el investigador por lo que se ha de intentar contactar con el equipo creativo de las agencias de traducción que realizaron la traducción de los anuncios de la muestra para que nos los faciliten.
} 


\section{CONCLUSIONES}

Se han publicado, como hemos visto, estudios sobre la metáfora en general que poco o nada aportan a la expresión metafórica no verbal o multimodal, ya que se han ceñido a la metáfora como expresión verbal únicamente. También son frecuentes, aunque cada vez menos, los estudios retoricistas de la metáfora publicitaria, sobre todo en estudios sobre la traducción publicitaria, y sólo recientemente, y desde el campo de la lingüística cognitiva, sola o en conjunción con la pragmática, se da cuenta del valor cognitivo y pragmático de la figura en el discurso publicitario (Samaniego Fernández 2002, 2007; Schäffner 2004). Se echa en falta, no obstante, una visión integrada de la metáfora que alcance a explicar la metáfora en sus múltiples facetas en el discurso publicitario a nivel discursivo (más concretamente semiótico), cognitivo y pragmático y su trasvase interlingüístico a otras lenguas y culturas.

En este artículo partiendo de la hipótesis de que la metáfora publicitaria es traducible en tanto en cuanto se le puede dar respuesta discursiva, cognitiva y pragmática a nivel interlingüístico, hemos planteado, sirviéndonos de aproximaciones polisistémicas, la Escuela de la Manipulación, así como el enfoque funcionalista, la corriente comunicativa e intercultural y la aproximación de la traducción subordinada, una posible metodología de análisis de diferentes factores intratextuales e intertextuales que influyen en el trasvase interlingüístico de la metáfora en el discurso publicitario y que combinan modelos de análisis textual orientados a la traducción, los postulados de la lingüística del texto y el análisis del discurso, la textología y la retórica contrastivas, desde una perspectiva traductológica eminentemente funcional. Esta metodología puede permitir, a la postre, ofrecer una sistematización de las posibilidades traslativas de la figura en el discurso publicitario, una vez aplicada a muestras concretas de trasvase interlingüístico de metáforas publicitarias en pares determinados de lenguas. Posteriormente se pueden usar muestras más amplias, por ejemplo, de textos publicitarios en diversos canales y/o lenguas diferentes. Sólo así se podrá dar solución al difícil trasvase interlingüístico que supone la metáfora en el discurso publicitario.

\section{REFERENCIAS BIBLIOGRÁFICAS}

Aarts, J. M. y J. P. Calbert 1979. Metaphor and Non-Metaphor: The Semantics of Adjective-Noun Combinations. Tübingen: Niemeyer.

Al Harrasi, A. 2000. "Metaphor in (Arabic-into-English) translation with specific reference to metaphorical concepts and expressions in political discourse". Unpublished Ph D. thesis, Aston University, Birmingham.

Álvarez Calleja, A. 1993. “On translating metaphor”. Meta 38, 3: 479-490.

Azar, M. 1989. “La métaphore traduisible”. Meta 34, 4: 794-796.

Boquera Matarredona, M. E. 2000. "La traducción de metáforas en un texto de divulgación médica". Ibérica 2: 13-25.

Bueno García, A. 2000 “ "Publicidad y traducción”. Vertere: Monográficos de la Revista Hermeneus de la Facultad de Traducción e Interpretación de Soria. 
Campos Pardillos, M. A. 1998. "Advertising discourse: when do we translate, and how?” II Estudios sobre traducción e interpretación. Eds. L. FÉLIX FERnÁNDEZ y E. Ortega ArJonilla. Málaga: Universidad de Málaga.

Cook, G. 2001. (2 $2^{\mathrm{a}}$ ed.). The Discourse of Advertising. London, New York: Routledge.

CORPAs PAstor, G. 2002. "Metodología de análisis y documentación para la traducción de textos publicitarios". En torno a la traducción-adaptación del mensaje publicitario. Coords. G. Corpas Pastor, A. Martínez García y M. C. Amaya Galván. Málaga: Universidad de Málaga. 131-161.

Cristofoli, M.; G. Dyrberg y L. Stage. 1998. "Metaphor, meaning and translation". Hermes, Journal of Linguistics 20: 165-179.

Dagut, M. 1976. “Can Metaphor be Translated?" Babel 12, 1: 21-33.

DobrzYNSKA, T. 1995. "Translating Metaphors: Problems of meaning”. Journal of Pragmatics 24: 595-604.

Duro Moreno, M. 2001. Traducir publicidad o el arte de pasar hambre. Granada: Comares.

EDWARDS, M. 2002. “CÓmo traducir la persuasión?” En torno a la traducción-adaptación del mensaje publicitario. Coords. G. Corpas Pastor, A. Martínez García y M. C. Amaya Galván. Málaga: Universidad de Málaga. 115-130.

Even-Zohar, I. 1979. "Polysystem Theory”. Poetics Today I (1-2): 287-310.

Even-Zohar, I. 1981. "Translation Theory Today. A Call for Transfer Theory”. Poetics Today II, 2, 4: 1-7.

FairClough, N. 1989. Language and Power. London: Longman. 1995. Critical Discourse Analysis. London: Longman.

Forceville, C. 1996. Pictorial Metaphor in Advertising. London \& New York: Routledge.

. 2002. "Further thoughts on delimiting pictorial metaphor". Theorie et Historia Scientiarum. An International Journal of Interdisciplinary Studies 1(1): 213-227.

. 2004. "The role of non-verbal sound and music in multimodal metaphor". Words in Their Places: A Festschrift for J. Lachlan Mackenzie. Eds. H. AERTSEN, M. HANNAY y R. LYALL. Amsterdam: Faculty of Arts, VU Amsterdam. 65-78.

2006. "Non-verbal and multimodal metaphor in a cognitivist framework: Agendas for research". Cognitive Linguistics: Current Applications and Future Perspectives. Eds. G. Kristiansen, M. Achard, R. Dirven y F. J. Ruíz de Mendoza IBÁÑEZ. Berlin and New York: Mouton de Gruyter. 379-402.

Fuertes Olivera, P. A. y E. Samaniego Fernández 1998. "Metaphor and Motivation: A Study of English Informal Phraseological Units". Lexicology 4, 1: 35-59. 
Fuertes Olivera, P. A. y M. Velasco Sacristán. 2001. "The translatability of metaphor in LSP: Application of a decision-making model". Revista Alicantina de Estudios Ingleses 14: 73-91.

Fuertes-Olivera, P. A. e I. Pizarro SÁnchez. 2002. "Translation and 'similarity-creating metaphors' in specialised languages". Target 14, 1: 43-73.

Fung, M. M. y K.L. Kiu. 1987. "Metaphor across language and culture". Babel 33, 2: 84-101.

GodDard, A. 1998. The Language of Advertising. London \& New York: Routledge.

Hatim, B. e I. Mason. 1990. Discourse and the Translator. London: Routledge. 1997. The Translator as Communicator. London: Routlege.

House, J. 1977. “A Model for Assessing Translation Quality”. Meta 22, 2: 103-109.

1981 ( $2^{\circ}$ ed.). A Model for Translation Quality Assessment. Tübingen: Gunter Narr Verlag.

IndurkhyA, B. 1992. Metaphor and Cognition: Studies in Cognitive Studies. Dordrecht: The Netherlands: Kluwer Academic Publishers.

Knowles, M. y R. Moon. 2006. Introducing Metaphor. New York: Routledge.

KURTH, E. 1995. "Altered images: cognitive and pragmatic aspects of metaphor translation”. Conference on Literary Translation (Warwick University, Dec. 1994), Leuven: CETRA.

Lakoff, G. y M. Johnson. 1980. Metaphors We Live By. Chicago: The University of Chicago Press.

Lakoff, G. y M. Turner. 1989. More than Cool Reason: A Field Guide to Poetic Metaphor. Chicago: Chicago University Press.

LARSON, M. L. 1989. La traducción basada en el significado. Buenos Aires: Eudeba.

MacCormac, E. R. 1985. A Cognitive Theory of Metaphor. Cambridge (Massachussets): M.J.T. Press.

Martínez Belchí, E. y R. Rocamora. 2005. "Lost in translation. Metáfora cognitiva y traducción de eslóganes". Comunicación presentada en el IV Congreso Internacional de AELFE (Asociación Española de Lenguas para Fines Específicos).

Mason, K. 1982. "Metaphor and Translation". Babel 28, 3: 140-149.

Mayoral Asensio, R., D. Kelly y N. Gallardo San Salvador. 1986. "El concepto de "traducción subordinada" (cómic, cine, canción, publicidad). Perspectivas no lingüísticas de la traducción (I)". Pasado, presente y futuro de la lingüística aplicada en España (Actas del II Congreso Nacional de Lingüística Aplicada (AESLA), Ed. F. FERNÁNDEZ. Valencia, abril 1985:95-105.

1998. "Concept of constrained translation. Non-linguistic perspectives of translation”. Meta XXXIII: 56-367. 
1999. "La traducción de la variación lingüística". Vertere. Monográficos de la Revista Hermeneus de la Facultad de Traducción e Interpretación de Soria: 1.

MenACERE, M. 1992. “Arabic metaphor and idiom in translation”. Meta 37, 3: 567-572.

Newmark, P. 1988. A Textbook of Translation. London: Prentice Hall International Limited.

1991. About Translation. London: Multilingual Matters Limited.

NidA, E. A. y Ch. R. TABer 1969. The Theory and Practice of Translation. Leiden: E.J. Brill.

Nord, C. 1994. “Traduciendo funciones”. Estudis sobre la traducció. Ed A. HuRTADo ALBIR. Castellón de la Plana: Universitat Jaume I. 97-112.

OCAÑA, F. e I. Yanguas. 2002. "Prólogo". En torno a la traducción-adaptación del mensaje publicitario. Coords. G. Corpas Pastor, A. Martínez García y M.C. Amaya Galván (Coods.). Málaga: Universidad de Málaga. 5-7.

Ortony, A. 1979. Metaphor and Thought. Cambridge, M.A.: Cambridge University Press.

Pisarska, A. 1989. Creativity of Translators. The Translation of Metaphorical Expressions in Non-literary Texts. Poznan: Uniwersytet I. Adama Mickicwicza: W. Poznaniu.

Pliego SÁnchez, I. (1993). "La traducción de la metáfora". Essays on translation 1: 97-103.

Rabadán Álvarez, R. 1991. Equivalencia y traducción. Problemática de la equivalencia translémica inglés-español. León: Servicio de Publicaciones de la Universidad de León.

REISS, K. y H. J. VERMEER. 1984 (Trad. 1996). Fundamentos para una teoría funcional de la traducción. Madrid: Akal. Trad. S. García y C. Martín. 1984. Grundlebung einer allgemeinen Translationstheory. Tubinga: Niemeyer.

Richards, I. A. 1936. The Philosophy of Rhetoric. New York: Oxford University Press.

SAmaniego Fernández, E. 1996. La traducción de la metáfora. Universidad de Valladolid: Servicio de Publicaciones e Intercambio Científico.

1998a. "Estudios sobre la metáfora I: la traducción de la metáfora". Espéculo 8 , marzo-junio. http://www.ucm.es/info/especulo/numero8/e_saman1.html (15 mayo 2008).

1998b. "Estudios sobre la metáfora II: la metáfora y los estudios de traducción”. Espéculo 9, julio-octubre. http://www.ucm.es/info/especulo/numero9/e_sam no.html. (15 mayo 2008). http://www.ucm.es/info/especulo/numero9/e_saman3. html. (15 mayo 2008).

http://www.ucm.es/info/especulo/numero9/e_saman4.html (15 mayo 2008).

http://www.ucm.es/info/especulo/numero9/e_saman5.html (15 mayo 2008). 
http://www.ucm.es/info/especulo/numero9/e_samanf.html (15 mayo 2008).

. 2000. "Diseño y aplicación de un marco de análisis de la traducción de la metáfora". Universidad de Alicante: Tesis doctoral inédita.

. 2002. "Prescripción y descripción: la metáfora en los estudios de traducción”. TRANS (Revista de Traductología de la Universidad de Málaga), 2: 47-61.

2007. "El impacto de la lingüística cognitiva en los estudios de traducción". Problemas lingüísticos en la traducción especializada. Ed. P. A. Fuertes Olivera. Valladolid: Servicio de Publicaciones e Intercambio Editorial de la Universidad de Valladolid: 119-154.

SCHÄFFNER, C. 1997. "Metaphor and interdisciplinary analysis". Journal of Area Studies 11: 57-72.

1998. "Metaphern". Handbuch Translation.Stauffenburg. Eds M. SNELLHornby, H. G. Hönig, P. Kubmaul y P. D. Schmitt. Tübingen. 280-285.

2004. "Metaphor and translation: some implications of a cognitive approach". Journal of Pragmatics 36: 1253-1269.

Searle, J. R. 1979. "Metaphor". The Philosophy of Language. Oxford: Ed. A. P. Martinish.

Snell-Hornby, M. 1988. Translation Studies: An Integrated Approach. Amsterdam: John Benjamins Publishing.

SteEn, G. 1999. "From linguistic to conceptual metaphor in five steps". Metaphor in Cognitive Linguistics. Ed R. W. Jr GibBS y G. J. SteEn. Amsterdam/Philadelphia: John Benjamins Publishing Company. 57-77.

Stienstra, N. 1993. YHWH is the Husband of his People. Analysis of a Biblical Metaphor with Special Preference to Translation. Kampen: KOK Pharos.

Sweetser, E.E. 1990. From Etymology to Pragmatics. Metaphorical and Cultural Aspects of Semantic Structure. Cambridge. Cambridge University Press. Cambridge Studies in Linguistics 54.

TAtilon, C. 1990. "Le texte publicitaire. Traduction ou adaptation?" Meta XXXV: 243-246.

TORRE, E. 1994. Teoría de la traducción literaria. Madrid: Síntesis.

TOuRY, G. 1978. "The Nature and Role of Norms in Literary Translation". Literature and Translation: Essays on the Theory and Practice of Literary Translation. Ed. J.S. Holmes. The Hague, Paris: Mouton. 83-100.

1980. The Search of a Theory of Translation. Tel Aviv: Porter Institute for Poetics and Semiotics.

1995. "A Rationale for Descriptive Translation". The Manipulation of Literature: Studies in Literary Translation. Ed T. Hermans. London: Croom and Helm. 16-41. 
1995. Descriptive Translation Studies and Beyond. Amsterdam/Philadelphia: John Benjamins.

TrainOR, P. 2002. "Say it with words (Díselo con palabras)". En torno a la traducciónadaptación del mensaje publicitario. Coords. G. Corpas Pastor, A. MartínEz García y M.C. Amaya Galván. Málaga: Universidad de Málaga. 115-130.

UnGerer, F. 2000. "Muted metaphors and the activation of metonymies in advertising". Metaphor and Metonymy at the Crossroads: A Cognitive Perspective. Ed. A. Barcelona SÁnchez. Berlin/New York: Mouton de Gruyter. 321-340.

VALDÉs RodRÍGUEZ, C. 1997. "The role of translation in the production of advertisements”. Some Sundry Wits Gathered Together. I Congreso de Filoloxía Inglesa. Ed. S. G. Fernández-Corrugedo. A Coruña: Universidade da Coruña. 221-226.

. 1998a. "La traducción publicitaria como acto de comunicación intercultural”. Tesis doctoral. Málaga: Universidad de Málaga.

.1998b. "Parámetros descriptivos de la traducción de textos publicitarios". Livius 12:193-202.

.2000. "Reception factors in multimedia translation: the case of advertisements". Translation in Context. Selected Contributions from the EST Congress, Granada 1998. Eds. A. Chesterman, N. Gallardo e Y. Gambier. Amsterdam/ Philadelphia: John Benjamins. 271-280.

.C. 2002a. "Parámetros teóricos en la traducción de la publicidad: un enfoque interdisciplinar". En torno a la traducción-adaptación del mensaje publicitario. Coords. G. Corpas Pastor, A. Martínez García y M. C. Amaya Galván. Málaga: Universidad de Málaga. 87-101.

. 2002b. "Estrategias traductoras en publicidad". En torno a la traducciónadaptación del mensaje publicitario. Coords. G. Corpas Pastor, A. Martínez García y M.C. Amaya Galván (Coods.). Málaga: Universidad de Málaga. 103-113.

Van Besien, F. y K. Pelsmaekers. 1988. "The translation of metaphor”.The Manipulation of Literature: Studies in Literary Translation. Ed T. Hermans. London: Croom and Helm. 16-41.

VAN DEN BRoECK, R. 1981. "The limits of translatability exemplified by metaphor translation". Poetics Today 2, 4: 73-87.

VANDAELE, S. (2002). "Traduction publicitaire médico-pharmaceutique et métaphores conceptuelles". Proceedings of the III Encontros de Tradução de Astra-FLUP. Eds. de B. Maia, J. Haller y M. Ulyrch. Porto: Facultade de Letras de Universidade do Porto. 329-339.

VÁzQuez-Ayora, G. 1977. Introducción a la traductología: Curso básico de traducción. Georgetown: Georgetown University Press.

Velasco Sacristán, M. 1999. "Publicidad y metáfora: análisis lingüístico de las metáforas de los eslóganes de anuncios de perfumes aparecidos en las ediciones hispana 
y británica de Cosmopolitan en 1998". Valladolid: Dpto de Lengua y Literatura Inglesa y Alemana. Trabajo de investigación inédito.

2003. "Publicidad y género. Propuesta, diseño y aplicación de un modelo de análisis de las metáforas de género en la publicidad impresa en lengua inglesa". Valladolid: Universidad de Valladolid. Tesis doctoral. http://wwwlib.umi.com/dissertations/fullcit/3076827 (15 mayo 2008).

Vermeer, H. 1989. "Skopos and commission in translational action". Readings in Translation Theory. Ed A. Chesterman. Helsinki: Oy Finn Lectura Ab. 221-232. 